\title{
Is it necessary to perform prophylactic cholecystectomy for all symptomatic gallbladder polyps diagnosed with ultrasound?
}

Mehmet Velidedeoğlu' ${ }^{1}$, Bülent Çitgez², Akif Enes Arıkan', Fadıl Ayan ${ }^{1}$

\section{ABSTRACT}

Cite this paper as: Velidedeoğlu M, Çitgez B, Arıkan AE, Ayan F. Is it necessary to perform prophylactic cholecystectomy for all symptomatic gallbladder polyps diagnosed with ultrasound? Turk J Surg 2017; 33(1): 25-28.

'Department of General Surgery, İstanbul University Cerrahpaşa School of Medicine, İstanbul, Turkey

${ }^{2}$ Clinic of General Surgery, Şişli Hamidiye Etfal Training and Research Hospital, ístanbul, Turkey

Address for Correspondence Bülent Çitgez e-mail: bcitgez@yahoo.com

Received: 27.06.2015 Accepted: 04.10 .2015 Available Online Date: 04.03.2016 OCopyright 2017 by Turkish Surgical Association Available online at www.turkjsurg.com
Objective: The main aim of this study is to determine the necessity of cholecystectomy in patients with ultrasound diagnosed symptomatic polypoid lesions of the gallbladder.

Material and Methods: The data of 82 patients with polypoid lesions of the gallbladder who had cholecystectomy between 2000 and 2012 were analyzed retrospectively with preoperative ultrasound and histopathology results.

Results: The mean age was $48.05 \pm 11.18$ years (range $25-74$ years). All patients underwent preoperative ultrasound examination. Eighteen (22\%) of the 82 patients were asymptomatic; their polypoid lesions of the gallbladder were detected with ultrasound during a check-up or other reasons. In 45 (55\%) of cases pathology reported no polypoid lesions of the gallbladder. Right upper quadrant or epigastric pain was the most common symptom (41.46\%) that led to hepatobiliary ultrasound, the other symptom was dyspepsia (36.59\%). On preoperative ultrasound evaluation, 22 patients had multiple polyps, and 9 of these 22 patients had at least 3 polyps.

Conclusion: There is an inaccuracy of ultrasound to detect polypoid lesions of the gallbladder. After diagnosing polypoid lesions of the gallbladder by using standard ultrasound, further pre-operative diagnostic tests are needed to help discriminating benign lesions from malignant ones, which may prevent unnecessary surgery regardless of symptoms.

Keywords: Cholecystectomy, gallbladder cancer, gallbladder polyps, ultrasound

\section{INTRODUCTION}

Polypoid lesions of the gallbladder (PLGs), are defined as immobile echoes protruding from the gallbladder wall into the lumen by ultrasonography (US), and the mass lesions occurred as a result of protrusion from the wall to the inside of the gallbladder, regardless of neoplastic potential (1). PLGs are often diagnosed incidentally following a routine abdominal ultrasound or cholecystectomy for other reasons as gallstones or biliary colic (1-3). The prevalence of PLGs in healthy people according to US findings is reported as 4.0-5.6\%. On the other hand the frequency in cholecystectomy specimens is between $2.6 \%$ and $12.1 \%$ (4-10). In 1970 a simplified classification of benign tumors and pseudotumors were offered that allows separation of neoplastic conditions from non-neoplastic ones on the basis of 180 cases together with the review of the literature (11). Benign tumors are epithelial tumors including papillary and nonpapillary adenomas, supporting tissue tumors including hemangioma, lipoma, leiomyoma, and granular cell tumor. Benign pseudotumors are hyperplastic lesions including adenomatous and adenomyomatous heterotropias including pancreas, liver, gastric and intestinal mucosa. Cholesterol and inflammatory polyps are the other benign pseudotumors. The last group also can be mentioned as miscellaneous including fibroxanthogranulomatous inflammation, parasitic infection and the others (11). Cholesterolosis and hyperplasia are the inflammatory polyps (3). Adenomas and carcinoma in situ are classified as neoplastic polyps and the rest are non-neoplastic, according to current accepted classification (12). Malign PLGs are gallbladder carcinomas (3). The increasing use of US and the improving resolution of abdominal imaging modalities led to discover PLGs more frequently (7, 13). Endoscopic ultrasound (EUS) makes very high-resolution images so will possibly play an important role in the management of gallbladder polyps (14). Unfortunately to detect the biological nature and differentiate tumorous polyps from nontumorous ones before the surgery is difficult, so the indication for cholecystectomy is not clear $(7,13)$. A summary of indications for surgery is in Table $1(6,15-17)$. The main aim of this study is to determine the necessity of cholecystectomy in patients with US diagnosed symptomatic PLGs. And the secondary outcomes of this study are clinical characteristics of subjects with PLGs, the diagnostic accuracy of ultrasound, and to investigate the operative indications.

\section{MATERIAL AND METHODS}

The records of 82 consecutive patients with PLGs, diagnosed by the US, who underwent either open cholecystectomy (OC) or laparoscopic cholecystectomy (LC) by one surgeon in Cerrahpaşa School of Medicine from 2000 to 2012, were reviewed retrospectively. Clinical data including age, sex, symptoms, and histopathological characteristics of the PLGs were collected. All the patients underwent US preoperatively. U.S. was performed by multiple operators The pathologic findings were classified according to Christensen and Ishak's system (11). 
Mobile, dependent echogenic foci within the gallbladder lumen with posterior acoustic shadowing in the ultrasonographic examination was accepted as criteria for the diagnosis of gallstones. Any mucosal projection into the lumen of the gallbladder that was fixed to the gallbladder wall and did not cast acoustic shadowing in the ultrasonographic examination was accepted criteria for the diagnosis of gallbladder polyps (18).

\section{Statistical Analysis}

All averages were denoted as mean \pm standart deviation. Student's t-test, Pearson's chi-square tests were used for comparisons. Statistics Package for Social Sciences 20.0 (IBM Corp., Armonk, NY, USA) was used for analysis. This study was conducted in accordance with the Helsinki Declaration. Patient constent forms were assigned and approval for this study was given by Ethical Committee of İstanbul University Cerrahpaşa School of Medicine.

\section{RESULTS}

Of the 82 patients 35 were male and 47 were female with a ratio of 0.74 . The mean age was $48.05 \pm 11.18$ years (range $25-74$ years). Patients underwent either OC $(n=4)$ or LC $(n=78)$. Sixtyfour of all patients (78.04\%) had some form of symptoms, while 18 (21.95\%) were asymptomatic. Right upper quadrant or epigastric pain was the most common symptom ( $n=34,41.46 \%)$ and dyspepsia ( $n=30,36.59 \%)$ was the other symptom.

According to the results of the histopathology there was no polyp [PLGs (-) group] in the gallbladder in $45(55 \%)$ of the 82

Table 1. Indications for cholecystectomy in PLGs patients (23)

\section{Highly recommend cholecystectomy}

\section{Any symptomatic patient (pain, flatulence, food intolerance,} and nausea)

Any patient with concomitant cholelithiasis

Polyp diameter $>1 \mathrm{~cm}$

Enlarging size of polyp between serial ultrasonograms

Consider cholecystectomy

Polyp diameter $0.6-1.0 \mathrm{~cm}$

Patient age $>50 \mathrm{yr}$

Single polyp vs. multiple polyps

Sessile polyp vs. pedunculated polyp

Observation acceptable (controversial)

Size $<0.5 \mathrm{~cm}$ and patient is not symptomatic

PLGs: Polypoid lesions of the gallbladder

Table 2. Histopathologic findings of PLGs and characteristics of patients

\begin{tabular}{|c|c|c|}
\hline Type & Female & Male \\
\hline \multicolumn{3}{|l|}{ Benign } \\
\hline Cholesterol polyp & $6(46.15)$ & $7(53.84)$ \\
\hline Cholesterolosis & $13(56.52)$ & $10(43.47)$ \\
\hline Papillar adenoma & $1(50)$ & $1(50)$ \\
\hline Gastric metaplasia & $2(66.6)$ & $1(33.33)$ \\
\hline Epitelial hiperplasia & $1(25)$ & $3(75)$ \\
\hline
\end{tabular}

PLGs patients who were preoperatively diagnosed by US. Of these, 35 patients had only chronic cholecystitis, 10 had gallstones. All patients who had gallstone in PLGs (-) group also had chronic cholecystitis. In PLGs (+) group (patients with histopathologically confirmed PLGs), there were 17 males and 20 females, whereas there were 18 males and 27 females in PLGs (-) group ( $p=0.588)$. Mean age was $50.70 \pm 11.78$ in PLGs (+) group and 45.87 \pm 10.27 in PLGs (-) group ( $p=0.051)$. In PLGs (-) group 19 patients had dyspepsia, 18 patients had right upper quadrant or epigastric pain, and 8 patients had no symptom where as in PLGs (+) group 11 patients had dyspepsia, 16 patients had right upper quadrant or epigastric pain, and 10 patients had no symptom. So symptom was not a helpful factor to differentiate each group $(p=0.425)$.

Thirteen (16\%) cholesterol polyps with a diameter of $3.94 \pm 2.83$ $\mathrm{mm}$ were found in which ten (54\%) were multiple lesions. All of them had a diameter of less than $10 \mathrm{~mm}$ and only one (14\%) of them was complicated by gallbladder stones. There were 23 cholesterolosis with a diameter less than $10 \mathrm{~mm}$, four (57\%) of them had concomitant gallstones. Three of the cholesterolosis were multiple lesions. Papillary adenoma was seen in two specimens with a diameter of 10 and $3 \mathrm{~mm}$. The specimen having $3 \mathrm{~mm}$ diameter lesion also had another smaller lesion. There were three gastric focal metaplasia lesions with a diameter less than $1 \mathrm{~mm}$. There were four epithelial hyperplasias with a diameter less than $3 \mathrm{~mm}$. One of them had multiple lesions. Non-neoplastic polyps include cholesterol polyps, inflammatory polyps (cholesterolosis and hyperplasia), and gastric metaplasia. Papillary adenoma was the only neoplastic polyp. There was no malignant polyp and one of the two neoplastic polyps (papillary adenomas) was symptomatic. Histopathological findings are denoted in Table 2-5.

In patients $\geq 50$ years-old, 20 patients had non-neoplastic polyps and two had neoplastic polyps whereas in patients younger than 50 years-old, 15 patients had non-neoplastic polyps and no patient had neoplastic polyp. Therefore, being over 49 years-old had no discriminatory effect on having neoplastic or non-neoplastic polyp $(p=0.23)$.

\section{DISCUSSION}

As a result of wide use of routine abdominal US, the frequency of detecting the elevated lesions of the gallbladder called PLGs has increased such as $4.0-5.6 \%$ in healthy subjects $(2,4,7,13)$. Adenomas and carcinoma in situ are classified as neoplastic polyps and the rest are non-neoplastic, according to current accepted classification (3). Malign PLGs are gallbladder carcinomas. In the previous literature (3) the occurrence of PLGs is equal in both sex, however in our study PLGs were more common in females ( $M: F=17: 20)$, a finding also suggested by recent studies $(4,19,20)$. PLGs were found most often in third to fifth decades of life in our study which was correlated with previous studies, besides a higher prevalence in 70 years old population was reported from Denmark (20). Although age is a significant factor that increases the probability of malignancy, our results did not confirm this, as there were 22 (59\%) patients with PLGs whose ages were over or equal to 50 years, and no malignant PLGs was seen in any patients $(6,7)$. There were only two patients over 50 years-old who had neoplastic polyps as adenomas.

Cholesterolosis is described as a submucosal deposit of esters of cholesterol chiefly in histiocytes. According to published reports, it has less surgical significance because it does not have an association with inflammation thus no severe symptoms 
are seen (21). However in our study 17 of 23 (74\%) patients were symptomatic, and there were concomitant gallstones only in four patients. So at least 13 patients had symptoms related with cholesterolosis. Cholesterol polyps, which are characteristically smaller than $10 \mathrm{~mm}$ and multiple, are the most common polypoid lesions and have no malignant potential (19). In our series, cholesterol polyps were smaller than $10 \mathrm{~mm}$ but were not the most common lesion.

As having the advantages of its accessibility and low cost, abdominal ultrasound seems to be the best available choice to detect the PLGs, besides has a technical limitation because of the intraobserver variability in interpretation $(3,22)$. U.S. examination is operator dependent and is less specific than the EUS most suitable for the evaluation and study of polypoid lesions of the gallbladder (PLGs) At the point of the size, polyps bigger than $5 \mathrm{~mm}$ are generally demonstrable with US (23). Endoscopic ultrasound (EUS) is superior to conventional US in differentiating polyps in the gallbladder ( $97 \%$ versus $76 \%)(24,25)$. The PLGs diagnosed by US can be missed even up to $60 \%$ by unenhanced computerized tomography (CT) scans (26). The sensitivity of CT decreases especially on the polyps smaller than $10 \mathrm{~mm}(3,27)$. In a study, a poor correlation was reported between ultrasonographic and pathological findings in the assessment of PLGs (28). Our study also reveals the inaccuracy of gallbladder US for the diagnosis of PLGs, thus the correct diagnosis by US confirmed with the pathology was $45.12 \%$. Even recent advances in the diagnostic imag-

Table 3. The disrubition of lesions

\begin{tabular}{|lccccc} 
& \multicolumn{2}{c}{ Numbers of } & \multicolumn{2}{c}{ Size of $(\mathrm{mm})$} \\
Lesions & Multiple & Single & $<10 \mathrm{~mm}$ & $>10 \mathrm{~mm}$ \\
\hline Nonneoplastic & 12 & 31 & 43 & 0 \\
\hline Neoplastic & 1 & 1 & 1 & 1 \\
\hline Total & 13 & 32 & 44 & 1 \\
\hline
\end{tabular}

mm: millimeter

Table 4. Histologic diagnosis and size of polypoid gallbladder lesions

\begin{tabular}{|lccccc}
$\begin{array}{l}\text { Size } \\
(\mathbf{m m})\end{array}$ & $\begin{array}{c}\text { Cholesterol } \\
\text { polyp }\end{array}$ & $\begin{array}{c}\text { Choles- } \\
\text { terolosis }\end{array}$ & $\begin{array}{c}\text { Adenoma } \\
\text { Hyperplasia }\end{array}$ & $\begin{array}{c}\text { Gastric } \\
\text { metaplasia }\end{array}$ \\
\hline$<10 \mathrm{~mm}$ & 13 & 23 & 1 & 4 & 3 \\
\hline$\geq 10 \mathrm{~mm}$ & 0 & 0 & 1 & 0 & 0 \\
\hline Total & 13 & 23 & 2 & 4 & 3 \\
\hline
\end{tabular}

mm: millimeter ing modalities rapidly develops, it is still difficult to differentiate tumorous polyps from non-tumorous ones before surgery, thus there is no general agreement about the indications for cholecystectomy $(3,7,13)$. Although the incidence of the carcinoma is low in PLGs, being afraid of developing cancerous changes of gallbladder polyps, surgery is preferred by also many patients and surgeons. On the other hand, there is a possible relation between the cholecystectomy and colon cancer risk according to many epidemiologic reports (29-32). The composition and secretion of the bile acid pool changes after cholecystectomy, the exposure of colonic mucosa to the carcinogenic secondary bile acids is a likely result $(33,34)$. Cholecystectomy also causes an increase of the incidence of gastritis as a result of bile regurgitation (35). There is no discussion on the indication of surgery for the symptomatic PLGs patients regardless of the size, however asymptomatic polyps is a dilemma for the clinician. In our study, in cholesterolosis group, seven of 23 patients (30\%) have dyspepsia, in one of them there was concomitant gallstone. Ten patients (43\%) had right upper quadrant or epigastric pain, in three of them there were concomitant gallstones, and six (26\%) had no symptoms. In cholesterol polyp group, four of 13 patients (31\%) had dyspepsia and there was no concomitant gallstone. Four patients (31\%) had right upper quadrant or epigastric pain, in one of them there was concomitant gallstone, and five (38\%) had no symptoms. So even there was no malignant potential, just because of having symptoms, surgery was preferred easily for the patients having cholesterolosis or cholesterol polyps. This study shows that there is an inaccuracy of US to detect the PLGs. According to the results of the histopathology it was seen that 45 of the 82 PLGs patients, who has diagnosed preoperatively by US, had no polyps in their gallbladders. These 45 patients had chronic cholecystitis and 10 of them had concomitant gallstones. So retrospectively we concluded that 35 patients should have not undergone surgery. Seventeen of 23 (73.91\%) patients in cholesterolosis group were symptomatic and there were concomitant gallstones only in four patients. So at least 13 patients had symptoms related with cholesterolosis. Eight of 13 (61.54\%) patients in cholesterol polyp group were symptomatic, and there was concomitant gallstone only in one patient. So at least 12 patients had symptoms related with cholesterol polyp. At least 25 patients underwent surgery just because of they were symptomatic, even they had benign lesions such as cholesterolosis and cholesterol polyps.

After detecting PLGs by the standard US, further diagnostic tests are needed to help discriminating benign lesions from malignant ones. The routine use of endoscopic EUS is recommended, because distinguishing signs for cholesterol polyps are possible with EUS (27). EUS has ability of stratifying polyps into high or low risk for malignancy and then can alter the decision of surgery due to having

Table 5. Patients characteristics

\begin{tabular}{|c|c|c|c|c|c|}
\hline & Cholesterol polyp & Cholesterolosis & Adenoma & Hyperplasia & Gastric metaplasia \\
\hline Mean age (years) & $49.69 \pm 12.64$ & $54.17 \pm 10.87$ & $62 \pm 2.66$ & $43.75 \pm 12.07$ & $52.33 \pm 17.04$ \\
\hline Number of men & 7 & 10 & 1 & 3 & 1 \\
\hline Number of women & 6 & 13 & 1 & 1 & 2 \\
\hline Number of patients with gallstones & 1 & 4 & 0 & 1 & 0 \\
\hline Numbers of patients with symptoms & 8 & 17 & 1 & 4 & 3 \\
\hline Dyspepsia & 4 & 7 & 0 & 2 & 1 \\
\hline Right epigastric pain & 4 & 10 & 1 & 2 & 2 \\
\hline No symptom & 0 & 6 & 0 & 0 & 0 \\
\hline
\end{tabular}


symptoms (22). By the use of EUS, many polyps can be confidently monitored with serial imagings instead of unnecessary surgery.

\section{CONCLUSION}

It must be thought again before deciding to make such an aggressive approach as cholecystectomy for PLG solely depending on US findings, with considering the disadvantages of the surgery and lack of an organ. The routine use of endoscopic EUS is strongly recommended for evaluating the PLGs.

Ethics Committee Approval: Ethics committee approval was received for this study from the ethics committee of İstanbul University Cerrahpaşa School of Medicine.

Informed Consent: Written informed consent was obtained from patient who participated in this study.

Peer-review: Externally peer-reviewed.

Author Contributions: Concept - M.V., F.A.; Design - M.V., B.C.; Supervision - M.V., B.C., F.A.; Materials - A.E.A.; Data Collection and/or Processing A.E.A., B.C.; Analysis and/or Interpretation - M.V., B.C., F.A.; Literature Search - A.E.A., B.C.; Writing Manuscript - M.V., B.C., A.E.A.; Critical Review - F.A.

Conflict of Interest: No conflict of interest was declared by the authors.

Financial Disclosure: The authors declared that this study has received no financial support.

\section{REFERENCES}

1. Okamoto M, Okamoto H, Kitahara F, Kobayashi K, Karikome K, Miura K, et al. Ultrasonographic evidence of association of polyps and stones with gallbladder cancer. Am J Gastroenterol 1999; 94: 446-450. [CrossRef]

2. Jorgensen T, Jensen KH. Polyps in the gallbladder. A prevalence study. Scand J Gastroenterol 1990; 25: 281-286.

3. Matos AS, Baptista HN, Pinheiro C, Martinho F. Gallbladder polyps: How should they be treated and when? Rev Assoc Med Bras 2010; 56: 318-321. [CrossRef]

4. Segawa K, Arisawa T, Niwa Y, Suzuki T, Tsukamoto Y, Goto H, et al. Prevalence of gallbladder polyps among apparently healthy Japanese: ultrasonographic study. Am J Gastroenterol 1992; 87: 630-633.

5. Edelman DS. Carcinoma of a gallbladder polyp: Treated by laparoscopic laser cholecystectomy. Surg Laparosc Endosc 1993; 3: 142-143.

6. Koga A, Watanabe K, Fukuyama T, Takiguchi S, Nakayama F. Diagnosis and operative indications for polypoid lesions of the gallbladder. Arch Surg 1988; 123: 26-29. [CrossRef]

7. Yang HL, Sun YG, Wang Z. Polypoid lesions of the gallbladder: Diagnosis and indications for surgery. Br J Surg 1992; 79: 227-229. [CrossRef]

8. Owada Y, Koyama K, Omokawa S, Goto H, Tanaka J, Sato T. Clinicopathological study of polypoid lesions of the gallbladder. Surgery 1983; 13: 1499-1506.

9. Chijiiwa K, Tanaka M. Polypoid lesion of the gallbladder: Indications of carcinoma and outcome after surgery for malignant polypoid lesion. Int Surg 1994; 79: 106-109.

10. Koga A, Watanabe K, Fukuyama T. Treatment of polypoid lesions of the gallbladder. Surgery 1983; 13: 1515-1519.

11. Christensen $\mathrm{AH}$, Ishak KG. Benign tumors and pseudotumors of the gallbladder. Report of 180 cases. Arch Pathol 1970; 90: 423-432.

12. Persley K. Acalculous cholecystitis, cholesterolosis, adenomyomatosis, and polyps of the gallbladder. In: Feldman M, Friedman LS, Sleisenger MH, eds. Sleisenger \& Fordtran's Gastrointestinal and Liver Disease : Pathophysiology, diagnosis, management. Philadelphia, PA: Saunders Elsevier 2006.p. 1450-1456.

13. Kubota K, Bandai Y, Noie T, Ishizaki Y, Teruya M, Makuuchi M. How should polypoid lesions of the gallbladder be treated in the era of laparoscopic cholecystectomy? Surgery 1995; 117: 481-487. [CrossRef]
14. Mishra G, Conway JD. Endoscopic ultrasound in the evaluation of radiologic abnormalities of the liver and biliary tree. Curr Gastroenterol Rep 2009; 11: 150-154. [CrossRef]

15. Koga A, Yamauchi S, Izumi Y, Hamanaka N. Ultrasonographic detection of early and curable carcinoma of the gallbladder. $\mathrm{Br} J$ Surg 1985; 72: 728-730. [CrossRef]

16. Rice J, Sauerbrei EE, Semogas P, Cooperberg PL, Burhenne HJ. Sonographic appearance of adenomyomatosis of the gallbladder. J Clin Ultrasound 1981; 9: 336-337. [CrossRef]

17. Ozmen MM, Patankar RV, Hengirmen S, Terzi MC. Epidemiology of gallbladder polyps. Scand J Gastroenterol 1994; 29: 480. [CrossRef]

18. Choi SY, Kim TS, Kim HJ, Park JH, Park DI, Cho YK, et al. Is it necessary to perform prophylactic cholecystectomy for asymptomatic subjects with gallbladder polyps and gallstones? J Gastroenterol Hepatol 2010; 25: 1099-1104. [CrossRef]

19. Terzi C, Sokmen S, Seckin S, Albayrak L, Ugurlu M. Polypoid lesions of the gallbladder: Report of 100 cases with special reference to operative indications. Surgery 2000; 127: 622-627. [CrossRef]

20. Jorgensen T, Kay L, Schultz-Larsen K. The epidemiology of gallstones in a 70-yearold danish population. Scand J Gastroenterol 1990; 25: 335-340. [CrossRef]

21. Womack NA. Pathological changes in chronic cholecystitis and the production of symptoms. Surgery 1938; 4: 847-855.

22. Gallahan WC, Conway JD. Diagnosis and management of gallbladder polyps. Gastroenterol Clin North Am 2010; 39: 359-367. [CrossRef]

23. Chattopadhyay D, Lochan R, Balupuri S, Gopinath BR, Wynne KS. Outcome of gall bladder polypoidal lesions detected by transabdominal ultrasound scanning: A nine year experience. World J Gastroenterol 2005; 11:2171-2173. [CrossRef]

24. Sugiyama M, Atomi Y, Yamato T. Endoscopic ultrasonography for differential diagnosis of polypoid gall bladder lesions: Analysis in surgical and follow up series. Gut 2000; 46: 250-254. [CrossRef]

25. Sugiyama M, Xie XY, Atomi $Y$, Saito M. Differential diagnosis of small polypoid lesions of the gallbladder: The value of endoscopic ultrasonography. Ann Surg 1999; 229: 498-504. [CrossRef]

26. Furukawa H, Kosuge T, Shimada K, Yamamoto J, Kanai Y, Mukai K, et al. Small polypoid lesions of the gallbladder: Differential diagnosis and surgical indications by helical computed tomography. Arch Surg 1998; 133: 735-739. [CrossRef]

27. Yang LP, Yang ZL, Tan XG, Miao XY. Expression of annexin a1 (anxa1) and 22 (anxa2) and its significance in benign and malignant lesions of gallbladder. Zhonghua Zhong Liu Za Zhi 2010; 32: 595-599.

28. Covarrubias C, Merino G, Cruz F, Pablo del Rio P, Vallespir A, Duarte I, et al. Correlation between ultrasound and pathology of the gallbladder. Rev Med Chil 1992; 120: 1227-1230.

29. Schernhammer ES, Leitzmann MF, Michaud DS, Speizer FE, Giovannucci E, Colditz GA, et al.. Cholecystectomy and the risk for developing colorectal cancer and distal colorectal adenomas. Br J Cancer 2003; 88: 79-83. [CrossRef]

30. Giovannucci E, Colditz GA, Stampfer MJ. A meta-analysis of cholecystectomy and risk of colorectal cancer. Gastroenterology 1993; 105: 130-141. [CrossRef]

31. Bollschweiler E, Feussner H, Huber F, Siewert JR. Is cholecystectomy a risk factor for colorectal cancer? A meta-analysis. Langenbecks Arch Chir 1993; 378: 304-312.

32. Lagergren J, Ye W, Ekbom A. Intestinal cancer after cholecystectomy: Is bile involved in carcinogenesis? Gastroenterology 2001; 121: 542-547. [CrossRef]

33. Koga S, Kaibara N, Takeda R. Effect of bile acids on 1,2-dimethylhydrazine-induced colon cancer in rats. Cancer 1982; 50: 543547.

34. Narisawa T, Magadia NE, Weisburger JH, Wynder EL. Promoting effect of bile acids on colon carcinogenesis after intrarectal instillation of n-methyl-n'-nitro-n-nitrosoguanidine in rats. J Natl Cancer Inst 1974; 53: 1093-1097. [CrossRef]

35. Chen Y, Wang Z. Cholelithiasis and cholecystectomy for colorectal cancer: A retrospective analysis. Zhonghua Wai Ke Za Zhi 1998; 36: 649-651. 